\title{
Rothmund-Thomson syndrome and osteoma cutis in a patient previously diagnosed as COPS syndrome
}

\author{
M. C. van Rij ${ }^{1}$ - M. L. Grijsen ${ }^{2}$ N. M. Appelman-Dijkstra ${ }^{3}$ • K. B. M. Hansson ${ }^{1}$ • \\ C. A. L. Ruivenkamp ${ }^{1} \cdot$ K. Mulder $^{2} \cdot$ R. van Doorn ${ }^{2}$ A. P. Oranje ${ }^{4}$ - S. G. Kant ${ }^{1}$
}

Received: 1 April 2016/Revised: 12 December 2016/Accepted: 18 December 2016/Published online: 30 December 2016

(C) The Author(s) 2016. This article is published with open access at Springerlink.com

\begin{abstract}
We present a patient with poikiloderma, severe osteoporosis and a mild intellectual disability. At the age of 9 years, this patient was proposed to suffer from a novel disease entity designated as calcinosis cutis, osteoma cutis, poikiloderma and skeletal abnormalities (COPS) syndrome. At the age of 35, he was diagnosed with Hodgkin's lymphoma. Recently, biallelic pathogenic variants in the RECQL4 gene were detected (c.1048_1049delAG and c.1391-1G>A), confirming a diagnosis of Rothmund-Thomson syndrome (RTS). In the brother of this patient, who had a milder phenotype, a similar diagnosis was made.

Conclusion: We conclude that COPS syndrome never existed as a separate syndrome entity. Instead, osteoma cutis may be
\end{abstract}

Revisions received: 1 November 2016; 13 December 2016; 8 December 2016

Arnold P. Oranje has passed away shortly before submitting the final version of the paper.

Communicated by Jaan Toelen

M. C. van Rij

m.c.vanrij@lumc.nl

M. L. Grijsen

m.l.grijsen@lumc.nl

N. M. Appelman-Dijkstra

N.M.Appelman-Dijkstra@lumc.nl

K. B. M. Hansson

K.B.M.Hansson@lumc.nl; klaassen_hansson@hotmail.com

C. A. L. Ruivenkamp

C.Ruivenkamp@lumc.nl

K. Mulder

K.M.Mulder@lumc.nl

R. van Doorn

R.van_Doorn@1umc.nl regarded as a novel feature of RTS, whereas mild intellectual disability and lymphoma may be underreported parts of the phenotype.

What is new:

- Osteoma cutis was not a known feature in Rothmund-Thomson patients.

- Intellectual disability may be considered a rare feature in RTS; more study is needed.

\section{What is known:}

- RTS is a well-described syndrome caused by mutations in the RECQL4 gene.

- Patients with RTS frequently show chromosomal abnormalities like, e.g. mosaic trisomy 8. arnold.oranje@gmail.com

S. G. Kant

S.G.Kant@lumc.nl

1 Department of Clinical genetics, Leiden University Medical Centre, Postzone K5-R, PO box 9600, 2300 RC Leiden, The Netherlands

2 Department of Dermatology, Leiden University Medical Centre, Leiden, The Netherlands

3 Department of Endocrinology, Leiden University Medical Centre, Leiden, The Netherlands

4 Kinderhuid.nl Teledermatology, Rotterdam, Dermicis Skin Clinic Alkmaar, Practice for Hair and skin, Breda, The Netherlands 
Keywords Rothmund-Thomson syndrome · Poikiloderma · RECQL4 gene · Mental retardation/developmental delay/ intellectual disability · Osteoporosis · Aneuploidy · Chromosomal instability $\cdot$ COPS syndrome $\cdot$ Osteoma cutis · Calcinosis cutis

$\begin{array}{ll}\begin{array}{l}\text { Abbreviations } \\ \text { BMD }\end{array} & \begin{array}{l}\text { Bone marrow density } \\ \text { COPS syndrome } \\ \text { Calcinosis cutis, osteoma cutis, } \\ \text { poikiloderma and skeletal abnormalities } \\ \text { Deoxyribonucleic acid } \\ \text { FISH }\end{array} \\ \text { Fluorescent in situ hybridisation } \\ \text { LSI MYC } & \text { Intellectual disability } \\ & \text { Locus-specific identifier (LSI) MYC, } \\ & \text { 2 FISH probes used to visualise locus } \\ \text { 8q24 on chromosome 8 } \\ \text { RECQL4 } & \text { DNA helicase, RECQ-like, type 4 } \\ \text { RTS } & \text { Rothmund-Thomson syndrome }\end{array}$

\section{Case description}

A 34-year-old man with dysmorphic features, osteoporosis and recurrent fragility fractures with non-union was referred to the department of clinical genetics. At age 9, a clinical diagnosis of calcinosis cutis, osteoma cutis, poikiloderma and skeletal abnormalities (COPS syndrome) was made and reported in this journal [11]. In summary, he had dysmaturity (birth weight $2400 \mathrm{~g}$ at 40 weeks gestational age) and severe diarrhoea requiring parenteral feeding. At the age of 3 , he suffered from meningitis due to mumps infection. Furthermore, at the age of 4, subcutaneous tumours, osteomas, with a maximal diameter of $3 \mathrm{~cm}$ were removed from the ankles, knees and forehead. Skeletal abnormalities were observed with hypoplastic patellae and delayed bone maturation. At the age of 15 years, a diagnosis of coeliac disease was made for which he was started on a diet and vitamin D supplementation. He suffered from multiple fragility fractures of both the tibiae, the right elbow, the left patella and the metatarsal bone $\mathrm{V}$ of his right foot, complicated by pseudo arthroses. A bone mass density measurement was performed at age 27 , showing a T-score of -2.6 femur and 2.4 lumbar vertebrae, consistent with a diagnosis of osteoporosis. Treatment with alendronate was initiated and while on treatment his bone mass increased and no fractures occurred. Treatment was discontinued at the age of 30 and at age 34 . He suffered from a mild intellectual disability for which he attended special educational programs.

At age 34, he was referred to our hospital for a second opinion regarding his osteoporosis and non-union of a tibia fracture. Physical examination showed a slender man with a short stature (height $167 \mathrm{~cm},(-2.1 \mathrm{SDS})$, with a saddle nose, absence of

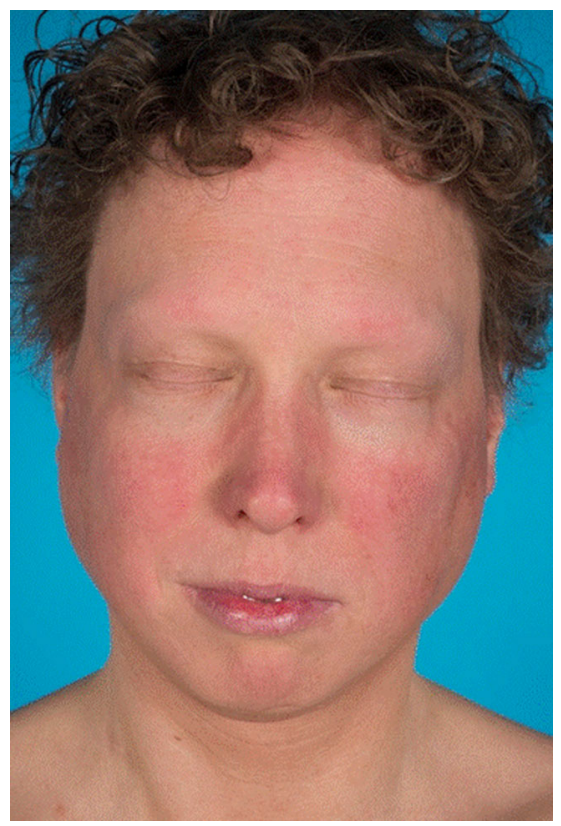

Fig. 1 Facial features at age 34. Note: absent eye brows and eye lashes, small nose

eyelashes and eyebrows and facial poikiloderma, (Fig. 1). He had sparse hair on the scalp, with two spots of alopecia areata and multiple small hyperpigmented macules on the trunk and arms. He had small but normal hands (Fig. 2); at the right foot, a partial 2-3 syndactyly of the right foot was observed.

His 5 years older brother has a milder phenotype, with a similar physical appearance and a mild intellectual disability. He was diagnosed with osteopenia and recurrent fragility fractures with non-union, but not with celiac disease (Table 1). Their parents were non-consanguineous.

Altogether, this presentation was compatible with a clinical diagnosis of Rothmund-Thomson syndrome (RTS, OMIM 268400).

Cytogenetic testing at the age of 13 showed a normal male karyotype in a total of 50 analysed nuclei without signs of

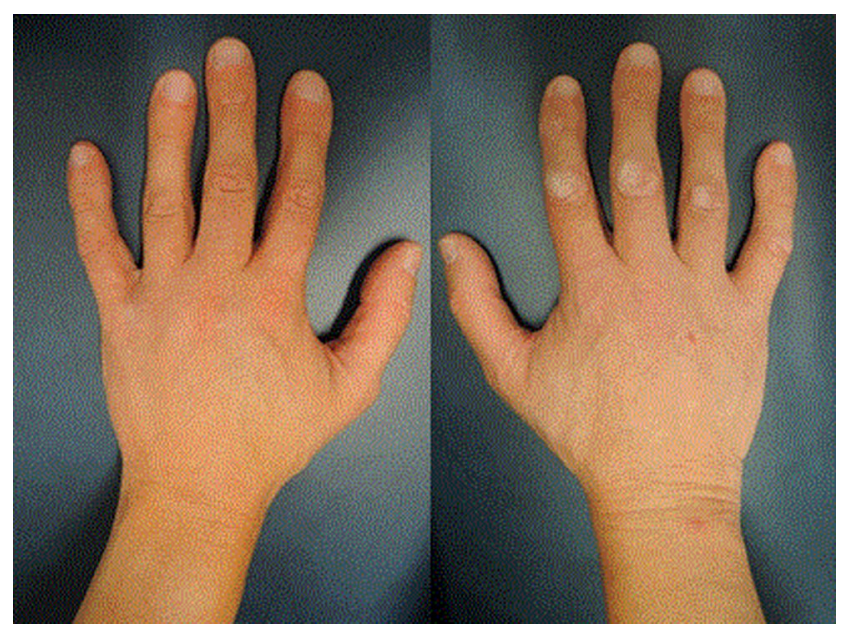

Fig. 2 Hands at age 34. Note: relatively small hands, with small though normally shaped nails, normal thumbs 
Table 1 Clinical features in our patient and his brother compared with the frequencies of these features among previously reported RothmundThomson patients

\begin{tabular}{|c|c|c|c|}
\hline & Our patient & Brother of the patient & Reported frequency of RTS features ${ }^{\mathrm{a}}$ \\
\hline \multicolumn{4}{|l|}{ Skin } \\
\hline Poikiloderma & + & + & All \\
\hline Hyperpigmentation & + & + & + \\
\hline Hypopigmentation & + & + & + \\
\hline Calcinosis cutis & + & - & Uncommon \\
\hline Osteoma cutis & + & - & - \\
\hline Palmoplantar hyperkeratosis & - & - & $30 \%$ \\
\hline Photosensitivity & - & - & $+/-$ \\
\hline Hair & & & $50 \%$ \\
\hline Sparse hair & + & + & \\
\hline Absent eyelashes & + & + & \\
\hline Sparse/absent eyebrows & + & + & \\
\hline Alopecia areata & + & - & \\
\hline Dental abnormalities & + & - & $27-59 \%$ \\
\hline \multicolumn{4}{|l|}{ Growth } \\
\hline Low birth weight & + & + & + \\
\hline Short stature & + & + & + \\
\hline Skeleton & & & $68-75 \%$ \\
\hline Radial ray defects & - & - & $20 \%$ \\
\hline Metaphyseal changes & + & - & + \\
\hline Osteopenia/osteoporosis & + & + & + \\
\hline Small patellae & + & - & + \\
\hline \multicolumn{4}{|l|}{ Ocular lesions } \\
\hline Cataract & - & - & $10-50 \%$ \\
\hline Gastrointestinal features & & & $17 \%$ \\
\hline Oesophageal or pyloric stenosis & + & - & \\
\hline Feeding problems & + & - & \\
\hline Chronic emesis/diarrhoea & + & - & \\
\hline Hematologic abnormalities & Hodgkin's lymphoma & - & Occasionally \\
\hline \multicolumn{4}{|l|}{ Cancer } \\
\hline Osteosarcoma & - & - & $30 \%$ \\
\hline Skin cancer & - & - & $5 \%$ \\
\hline Lymphoma & + & - & Two cases ${ }^{b}$ \\
\hline Neurocognitive development & & & No specific data available \\
\hline Mild intellectual disability & + & + & \\
\hline \multirow[t]{2}{*}{ Cytogenetic abnormalities } & Mosaic trisomy $8(15 \%)$ & Mosaic trisomy $8(13 \%)$ & Cases reported with Mosaic trisomy 2, 7 or 8 \\
\hline & $\begin{array}{l}\text { Mosaic isochromosome 8q } \\
(13 \%)^{c}\end{array}$ & $\begin{array}{l}\text { Mosaic isochromosome 8q } \\
(9 \%)^{c}\end{array}$ & Mosaic isochromosome 2,7 or 8 \\
\hline RECQL4 gene mutations & + & + & $66 \%$ \\
\hline
\end{tabular}

${ }^{\mathrm{a}}$ Frequencies derived from $[2,8,16,17]$

${ }^{\mathrm{b}}$ Cases reported by Siitonen 2009 and Simon 2010 [13, 14]

${ }^{\mathrm{c}}$ Based on interphase FISH (2 probes: LSI MYC, 8q24) on 400 lymphocytes nuclei in blood

chromosomal instability, while a CytoScan HD Array (Affymetrix) at the age of 34 showed a slight excess of chromosome 8q, suggestive for a mosaic chromosome 8q duplication (presumably between 12 and 18\%). Subsequently, karyotyping and FISH analysis were performed on cultured lymphocytes from both brothers, showing a mosaicism for trisomy 8 , isochromosome $8 \mathrm{q}$ and a normal karyotype (Table 1). Sanger sequencing of the RECQL4 gene (OMIM 603780) showed two compound heterozygous recurrent pathogenic mutations in both brothers: one frame shift mutation: 
c.1048_1049delAG (p.(Arg350fsX21)) and one splice site mutation c.1391-1G>A (p.(?)). Carrier testing in the parents confirmed biallelic inheritance. Altogether, these findings confirmed the clinical diagnosis of RTS in both brothers.

One year later, the index patient was diagnosed with a stage I Hodgkin's lymphoma in the neck for which he was started on three cycles of adriamycin, bleomycin, vinblastin, darcabazin and prednisone in combination with involved node radiation with $12 \times 1.8$ Gy resulting in a complete remission. He developed fever and neutropenia after the first chemotherapy. The neutropenia has resolved after a temporary break of chemotherapy and treatment with antibiotics. Neutropenia did not return after continuation of the ABVD therapy. The radiotherapy did not lead to considerable side effects.

\section{Discussion}

In this report, we presented a case of RTS alternatively diagnosed as COPS. RTS is a rare autosomal recessive genodermatosis with a distinctive phenotype, characterised by poikiloderma, sparse hair, skeletal abnormalities and an increased risk for osteosarcoma [8]. RTS had been considered, but was assumed less likely, due to the absence of cataract and photophobia, a major sign, and the presence of osteoma cutis, whereas genetic confirmation was not possible in that period [11]. However re-evaluation of the patient and his brother changed the diagnosis to RTS and later the cataract was not associated with RECQL4 mutations anymore.

The absence of the cataract makes the distinction between the two clinical variants of RTS: the form with poikiloderma and ocular defects, named RTSI, and poikiloderma, skeleton defects, predisposition to cancer and RECQL4 mutations, named RTSII, which accounts for approximately $66 \%$ of RTS patients (Table 1). Osteoma cutis has not been described before; calcinosis cutis has been linked to RTS $[1,4]$.

The RECQL4 gene on the long arm of chromosome 8 (8q24.3) codes for an ATP-dependent DNA helicase, which plays a role in regulating DNA replication, DNA repair and chromosomal integrity $[6,13]$. RECQL4-deficient mice show abnormal karyotypes and aneuploidy [10], as well as defects in osteoblast progenitors [18]. In patients with RTS, these defects in osteoblast progenitors make them prone to osteosarcoma and low-turnover osteoporosis with a predisposition for fracture non-union $[9,18]$. Chromosomal abnormalities, like the mosaic trisomy 8 and $\mathrm{i}(8 \mathrm{q})$ have been reported in RTS patients [7]. The specific RECQL4 mutations, c.1048 1049delAG in exon 5 and c.1391-1G>A in intron 7, were both previously reported in patients with RTS [3, 8]. One patient was reported with the exact combination of mutations; contrary to our patient, this patient showed additional humoral immune deficiency and granulomatous skin lesions [3].

Generally, intellectual disability is not considered to be a feature of RTS $[8,13,17]$. As a consequence, the number of
RTS patients with a mild intellectual disability, like our patients, may be underestimated. Mild to moderate intellectual disability has been reported in a small number of cases $[5,8$, $15,16]$. Co-occurring features like hydrocephalus and craniosynostosis may have played a role in the ID [16], and in some cases the diagnosis of RTS was not confirmed [5]. In our case, the history of meningitis may have attributed to some part of the intellectual disability; however, the brother was affected as well, implying a relationship with RTS. We hypothesised that the mosaic chromosomal abnormalities observed are responsible for the development of intellectual disability. However, the chromosomal imbalances were apparently acquired. Additionally, mutations in RecQ DNA helicase genes may mildly impact intellectual development, such as observed in Bloom syndrome (OMIM 210900), a chromosomal breakage syndrome, caused by mutations in the RECQL3 gene (OMIM 604610). Although most affected individuals with Bloom syndrome have normal intellectual ability, many exhibit learning disability [12]. Likewise, a relative mild intellectual disability, such as in our patients, may be underreported in RTS patients and considered to be normal variability of intelligence. Modifier genes and co-morbidity may also play a role in the variability and atypical expression with or without ID; these may explain the phenotypic differences between the brothers.

In conclusion, we reclassify a patient with COPS as RTS with osteoma cutis and a mild intellectual disability, refuting COPS as a separate entity, since there were no reports in literature after 1991. To link mild intellectual disability to RTS, more studies are needed.

Acknowledgments We are grateful to the patients and their family for their cooperation in this publication. Additionally, we thank Prof. Dr. M. Mearadji, Paediatric Radiologist, Erasmus Medical Centre Rotterdam, for proofreading and commenting on the radiologic findings, and Dr. Laura J.C.M. van Zutven, Department of Clinical genetics, Erasmus Medical Centre, Rotterdam, The Netherlands, for providing additional details on the chromosomal analysis performed at childhood.

Authors' contribution M.C. van Rij: involved in writing the case report, literature research.

M.L. Grijsen: dermatologist in training who was involved in the patients' dermatologic follow-up and description of the phenotype.

N.M. Appelman-Dijkstra: internist involved in treatment of osteoporosis of the patient, intellectually contributing to the article, and proofreading the english language.

K.B.M. Hansson: cytogeneticist involved in diagnosing the chromosomal abnormalities of both brothers and contributing to the description of these findings in the article.

C.A.L. Ruivenkamp: molecular geneticist involved in the array analysis and proofreading the article.

K. Mulder: dermatologist in training involved in the intellectual workup for the article.

R. van Doorn: supervising dermatologist specialised in genodermatologic syndromes, and contributing to the intellectual content of the article.

A.P. Oranje: dermatologist who wrote the initial case report (1991), now involved from a distance by proofreading the article. Sadly, this coauthor passed away very recently (Oct 19, 2016). 
S.G. Kant: clinical geneticist who first diagnosed the patient with RTS syndrome, and who contributed to the article by critical reading.

\section{Compliance with ethical standards}

Conflict of interest The authors declare that they have no conflict of interest.

Funding There was no funding applied to complete this case report. Informed consent of the patient involved was provided, including permission to publish pictures.

Open Access This article is distributed under the terms of the Creative Commons Attribution 4.0 International License (http:// creativecommons.org/licenses/by/4.0/), which permits unrestricted use, distribution, and reproduction in any medium, provided you give appropriate credit to the original author(s) and the source, provide a link to the Creative Commons license, and indicate if changes were made.

\section{Reference}

1. Aydemir EH, Onsun N, Ozan S, Hatemi HH (1988) RothmundThomson syndrome with calcinosis universalis. Int J Dermatol 27:591-592

2. Beghini A, Castorina P, Roversi G, Modiano P, Larizza L (2003) RNA processing defects of the helicase gene RECQL4 in a compound heterozygous Rothmund-Thomson patient. Am J Med Genet A 120A:395-399

3. De Somer L, Wouters C, Morren MA, De Vos R, Van Den Oord J, Devriendt K, Meyts I (2010) Granulomatous skin lesions complicating varicella infection in a patient with Rothmund-Thomson syndrome and immune deficiency: case report. Orphanet journal of rare diseases 5:37

4. Ertugrul H. Aydemir M.D.* NOMD, Sevil Ozan M.D. andHasan H. Hatemi M.D. (1969) Rothmund-Thomson syndrome with calcinosis universalis. Br J Dermatol 81:79-80

5. Gelaw B, Ali S, Becker J (2004) Rothmund-Thomson syndrome, Klippel-Feil syndrome, and osteosarcoma. Skelet Radiol 33:613-615

6. Kitao S, Shimamoto A, Goto M, Miller RW, Smithson WA, Lindor NM, Furuichi Y (1999) Mutations in RECQL4 cause a subset of cases of Rothmund-Thomson syndrome. Nat Genet 22:82-84
7. Larizza L, Magnani I, Roversi G (2006) Rothmund-Thomson syndrome and RECQL4 defect: splitting and lumping. Cancer Lett 232:107-120

8. Larizza L, Roversi G, Volpi L (2010) Rothmund-Thomson syndrome. Orphanet journal of rare diseases 5:2

9. Lu L, Harutyunyan K, Jin W, Wu J, Yang T, Chen Y, Joeng KS, Bae Y, Tao J, Dawson BC, Jiang MM, Lee B, Wang LL (2015) RECQL4 regulates p53 function in vivo during skeletogenesis. J Bone Miner Res 30:1077-1089

10. Mann MB, Hodges CA, Barnes E, Vogel H, Hassold TJ, Luo G (2005) Defective sister-chromatid cohesion, aneuploidy and cancer predisposition in a mouse model of type II Rothmund-Thomson syndrome. Hum Mol Genet 14:813-825

11. Oranje AP, de Muinck Keizer-Schrama SM, Vuzevski VD, Meradji M (1991) Calcinosis cutis, osteoma cutis, poikiloderma and skeletal abnormalities (COPS syndrome) - a new entity? Eur J Pediatr 150: 343-346

12. Sanz MMGJ (2006) Bloom's syndrome. In: Pagon RAAM, Ardinger $\mathrm{HH}$ et al (eds) GeneReviews ${ }^{\circledR}$ [Internet]. Seattle (WA). University of Washington, Seattle, pp. 1993-2015

13. Siitonen HA, Sotkasiira J, Biervliet M, Benmansour A, Capri Y, Cormier-Daire V, Crandall B, Hannula-Jouppi K, Hennekam R, Herzog D, Keymolen K, Lipsanen-Nyman M, Miny P, Plon SE, Riedl S, Sarkar A, Vargas FR, Verloes A, Wang LL, Kaariainen H, Kestila M (2009) The mutation spectrum in RECQL4 diseases. European journal of human genetics : EJHG 17:151-158

14. Simon T, Kohlhase J, Wilhelm C, Kochanek M, De Carolis B, Berthold F (2010) Multiple malignant diseases in a patient with Rothmund-Thomson syndrome with RECQL4 mutations: case report and literature review. Am J Med Genet A 152A:1575-1579

15. Vennos EM, Collins M, James WD (1992) Rothmund-Thomson syndrome: review of the world literature. J Am Acad Dermatol $27: 750-762$

16. Wang LL, Levy ML, Lewis RA, Chintagumpala MM, Lev D, Rogers M, Plon SE (2001) Clinical manifestations in a cohort of 41 Rothmund-Thomson syndrome patients. Am J Med Genet 102: $11-17$

17. Wang LL, Plon SE (1993) Rothmund-Thomson syndrome. In: Pagon RA, Adam MP, Ardinger HH, Bird TD, Dolan CR, Fong CT, Smith RJH, Stephens K (eds) GeneReviews(R), Seattle (WA)

18. Yang J, Murthy S, Winata T, Werner S, Abe M, Prahalad AK, Hock JM (2006) Recql4 haploinsufficiency in mice leads to defects in osteoblast progenitors: implications for low bone mass phenotype. Biochem Biophys Res Commun 344:346-352 